\title{
A screen-theory \\ e o espectador \\ cinematográfico: \\ um panorama crítico
}

\section{Resumo}

O presente texto aborda criticamente o papel do que se denomina de Screen-

Theory, no contexto da revista inglesa Screen, nos anos 70. na Inglaterra, quanto a deslocamentos conceituais que desde então marcaram a relação entre diferentes media e o espectador, sobretudo no que se refere ao cinema.

\section{Introdução}

Neste ensaio, proponho um mapeamento crítico da "screen-theory", o conjunto de reflexões elaborado na década de 70, no espaço editorial e institucional organizado em torno à revista britânica Screen, que tem como objeto central a relação entre o cinema dominante e o seu espectador ${ }^{1}$. Em que pesem suas hoje evidentes falácias epistemológicas e conceituais (homogeneização, binarismo, determinismo textual etc.), responsáveis por sua implosão teórica já ao final dos anos 70, a screen-theory tem um papel estratégico na história contemporânea não apenas dos estudos de cinema, como também dos estudos de mídia em geral. Screen aparece como a grande instauradora de um decisivo movimento de deslocamento operado ao longo do último quarto de século na teoria e pesquisa sobre cinema. Este movimento conduz, do ponto de vista institucional, o centro da reflexão desde a França para o mundo anglo-americano. E do ponto de vista teórico, leva as suas bases epistemológicas e metodológicas de um textualismo a um contextualismo.

A screen-theory se caracteriza justamente pela tradução e reelaboração crítica das teorias francesas da des- construção e do dispositivo, recémformuladas por Cinéthique e pelos Cahiers du Cinéma no pós-maio de 68. Prontamente obtém, na Inglaterra, e a seguir nos Estados Unidos, o mesmo reconhecimento canônico alcançado por suas matrizes continentais, consolidando a incipiente posição dos estudos de cinema nos meios acadêmicos locais. Os ensaístas de Screen vão se distinguir por seu perfil intensamente autocrítico, que determina inicialmente uma rápida evolução do corpus teórico, plena de inovações sobre a teorização de Cinéthique e dos Cahiers. Logo depois, no entanto, esta mesma autocrítica conduz à insustentabilidade do projeto teórico, exposto em contradições e falácias incontornáveis. Curiosamente, isto produz o ambiente perfeito à ascensão das correntes que configuram a atual liderança internacional do pensamento anglo-americano na teoria do cinema, ou seja, os estudos culturais - vanguarda teórica nos estudos de mídia como um todo, em razão de seu contextualismo e o cognitivismo.

Face a esta relevância histórica de seu corpus, é preocupante, portanto, a constatação da escassez de trabalhos no país, na área da história da teoria, contemplando a screen-theory. Minha principal intenção é a de colaborar para o preenchimento desta lacuna. Subsidiariamente, espero oferecer, com o mapeamento produzido, possibilidades para uma melhor apreciação do presente quadro em teoria do cinema. Neste sentido é que ordeno o mapeamento teórico em função do deslocamento epistemológico e metodológico antes apontado,

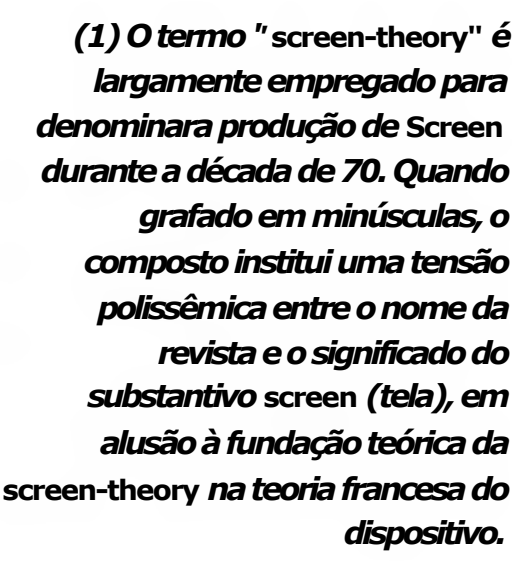

Fernando Mascarello é doutorando em Cinema pela Escola de Comunicações e Artes da Universidade de São Paulo e Membro do Conselho Executivo da SOCINE Sociedade Brasileira de Estudos de Cinema 
(2) O conceito de modernismo político é aunhado inicialmente por Syivia Harvey em "Whose Brecht? Memories for the eighties: a citical recovery", Screen 23, 1 (1982), e desenvolvido por David Rodowick em The crisis of political modernism: criticism and ideology in contemporary film theory (Berkeley: University of Califórnia Press, 1994). Várias outras denominações são utilizadas para dar conta do mesmo corpus teórico, como "paradigma MetzLacan-Althusser","subject-position theory" (teoria do posicionamento subjetivo) ou "teorias da homogeneidade", respectivamente em Francesco Casetti, Teorias del cine (Madri: Catedra, 1994), David Bordwell, "Contemporary film studies and the vicissitudes of Grand Theory", in David Bordwell e Noel Carroll (org.), Post-theory: reconstructing film studies

(Madison: University of Wisconsin Press, 1996), e Judith Mayne,

Cinema and spectatorship. (Londres: Routledge, 1993). Mayne faz ainda uso simplesmente do termo "teorias da década de 70".

(3) Cumpre lembrar que a revista Screen ainda hoje se mantém em intensa atividade, tendo acolhido diversas das novas tendências em teoria do cinema; é o corpus referido como screen-theory que tem seus limites históricos entre estas duas datas.

(4) Colin MacCabe, "Class of 68", in Tracking the signifier: theoretical essays: film, linguistics, literature (Minneapolis: University of Minnesota Press, 1985), pp. 7-12. de uma progressiva contextualização da teoria. Proponho este ordenamento na primeira seção, a partir do exame conjunto do desenvolvimento das teorias francesas do pós-maio de 68 e da screen-theory, entendidas como etapas sucessivas de um mesmo projeto teórico de um "modernismo político". Posso então identificar dois estágios principais na produção de Screen durante a década de 70, o "pós-brechtianismo cinematográfico" e a "dialética do sujeito", sobre os quais me detenho nas seções seguintes. Por fim, no epílogo, investigo as circunstâncias do esvaziamento da screen-theory, paralelo ao deslocamento, que se verifica no mainstream teórico anglo-americano, de seu textualismo ao ascendente contextualismo dos estudos culturais.

\section{O modernismo político.}

Tomadas em conjunto, as teorias francesas do pós-maio de 68 e a screentheory têm sido designadas, por historiadores da teoria como Sylvia Harvey e David Rodowick, com a denominação "modernismo político"2. Rodowick utiliza o termo para referir-se ao campo discursivo (noção tomada a Foucault) produzido por teóricos do cinema (Jean-Louis Baudry, Christian Metz, Laura Mulvey, Stephen Heath, etc.) e por cineastas da vanguarda político-semiológica (o Godard do grupo Dziga Vertov, Jean-Marie Straub e Danielle Huillet, Nagisa Oshima, Peter Gidal, etc.) entre o ano de 1969 e a segu da metade da década de 70 . O modernismo político promove a conhecida triangulação entre semiótica do cinema, marxismo althusseriano e psicanálise lacaniana que tem como objetivos a compreensão dos mecanismos de subjetivação ideológica do espectador pelo cinema dominante e a fundamentação do contracinema de vanguarda proposto.

Rodowick aponta como elemento delimitador do corpus teórico modernista-político o seu intenso determinismo textual, ou seja, a redução da relação cinema popular/espectador à condição de um evento aprioristicamente determinado pelo texto fílmico, à revelia do espectador concreto, absolutamente apassivado, e da história. Este textualismo é elaborado, evidentemente, a partir de uma ótica modernista (utilização de contra-estratégias semiológicas de vanguarda) e política (ataque aos mecanismos de subjetivação ideológica). Sendo assim, pode-se estabelecer como marco inaugural do modernismo político o momento em que o textualismo semiológico dos anos 60 se lança a compreender a subjetivação do espectador ao capitalismo (o célebre debate entre Cinéthique e os Cahiers, em 1969 e 1970), e como ponto de implosão o reconhecimento interno de que o determinismo textual é falacioso (o ensaio "Notes on Subjectivity", de Paul Willemen, publicado em Screen em 1978)

Enquanto estágio anglo-americano do projeto modernista-político, os limites históricos da screen-theory podem ser situados, portanto, por volta dos anos de 1971 (quando se iniciam as traduções dos ensaios de Cinéthique e dos Cahiers) e de 1978 (momento em que ocorre a ruptura epistemológica que conduz do textualismo ao con-

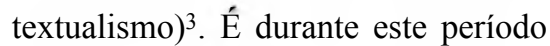
que a revista britânica, secundada por outras como Afterimage, October, Camera Obscura, m/f e Wide Angle, cumpre o processo de tradução e reelaboração das teorias francesas. Um mapeamento histórico-institucional do período é fornecido por Colin MacCabe, um dos diretores de Screen à época, em -seu artigo autobiográfico "Class of 68 ".

Ele o divide em três etapas: uma primeira empenhada na disponibilização de volumoso material não disponível em língua inglesa (escritos dos formalistas russos, dos estruturalistas tchecos e, principalmente, dos ensaístas de Cinéthique e dos Cahiers), entre 1971 e 1973; uma segunda de intensa produção teórica, quando são publicados os ensaios hoje clássicos da revista, entre 1974 e 1977; e uma última de dissenso teórico e crise editorial, quando vários ensaístas (inclusive ele) deixam a revista, a partir de $1978^{4}$.

Dado este ordenamento histórico-institucional, para que se possa construir um mapeamento propriamente 
histórico-teórico da screen-theory é preciso, porém, considerá-la não isoladamente, mas como parte integrante do campo discursivo mais abrangente do modernismo político. Os elementos ordenadores do mapeamento têm de ser definidos, pois, de modo a articular historicamente o desenvolvimento da reflexão em Screen com o da teorização francesa de Cinéthique e dos Cahiers que a precede. Em outras palavras, devese proceder a um exame preliminar das grandes linhas da história teórica modernista-política como um todo, para somente então dar início ao mapeamento da screen-theory em específico.

O modernismo político surge na França da conjunção de dois fatores: sobre um ambiente de crescente frustração com a incapacidade da semiótica metziana em equacionar anseios políticos, vem agir como elemento catalisador o maio de 68 cinematográfico, com sua postulação de um inadiável comprometimento entre política e teoria ${ }^{5}$ Duas indagações resumem as angústias da classe cinematográfica durante os événements de maio: "a primeira, como o cinema dominante contribui para a manutenção da estrutura social existente", e "a segunda, qual a forma apropriada para um cinema de oposição que rompa com a dominância ideológica do cinema comercial e transforme o filme de mercadoria em instrumento de mudança social"6. São elas que geram o duplo objetivo da teorização modernista-política, de compreender o cinema mainstream para então poder desconstruí-lo.

É com este intuito que Cinéthique e os Cahiers (a primeira revista de forma mais explícita que a segunda) empreendem a transposição, para o campo do cinema, da teoria literária ultra-modernista da revista francesa Tel Quel, o amálgama de semiologia, althusserianismo e lacanismo geralmente referido como "theorie d'ensemble". Este primeiro momento, o da teoria da desconstrução, que ocorre entre 1969 e 1970, caracteriza-se pelo intenso debate entre as duas revistas quanto ao grau de radicalização teórica a ser implantado, tendendo os Cahiers a serem mais transigentes. A disputa opõe ensaístas como Jean-Paul Fargier e Gerard Leblanc (Cinéthique) e a dupla Jean-Louis Comolli/Jean Narboni (Cahiers) ${ }^{7}$. Investiga-se a produção textual da impressão de realidade cinematográfica, que é apontada, em seu ocultamento, como elemento chave no processo de interpelação (Althusser) e conseqüente posicionamento subjetivo do espectador na ideologia burguesa. Visando à desconstrução deste mecanismo textual, postula-se um cinema revolucionário não apenas quanto ao conteúdo, mas sobretudo quanto à forma. É a conhecida "política da forma", que alia trabalho sobre o significante e trabalho sobre o significado ${ }^{8}$.

Este formalismo político ganha uma segunda etapa, a da teoria do dispositivo, nos escritos de Jean-Louis Baudry em Cinéthique, em especial em seu ensaio clássico "Cinéma: effets idéologiques produits par l'appareil de base", de $1970{ }^{9}$. Partindo da reflexão desconstrutiva, Baudry propõe a idéia de que, aos procedimentos textuais ilusionistas, fundados na perspectiva artificialis e na continuidade, somam-se os efeitos da situação de projeção. Esta, ao reencenar a cena infantil do estágio do espelho (Lacan), reforça o espectador em sua condição de sujeito burguês, devido à sua assunção de um status absolutamente imaginário ou ideológico de entidade constitutiva da realidade, a que o autor denomina "sujeito transcendental". Baudry formula, assim, uma concepção de espectador que, na teoria da desconstrução, se encontra ainda apenas implícita. Além disso, introduz conceitos tomados diretamente a Lacan, presentes até então somente como fundamento à noção althusseriana de interpelação ${ }^{10}$.

Esta teorização francesa apresenta três desdobramentos principais antes de seu translado ao mundo angloamericano. Inicialmente, por volta de 1972, Cinéthique faz uma auto-crítica ao excessivo formalismo de seu modernismo, vindo a romper com Tel Quel ${ }^{11}$. Apregoa, então, um retomo à ênfase sobre o conteúdo em detrimento da forma, o que a aproxima, em um certo sen-
(5) Para um relato completo do maio cinematográfico e de suas conseqüências sobre o

desenvolvimento da teoria do cinema, ver Sylvia Harvey, May 68 and film culture (London: British Film Institute, 1978).

(6) Robert Lapsley e Michael Westlake, Film theory: an introduction (Manchester:

Manchester University Press, 1988), p.1-2.

(7) Os ensaios mais representativos do debate são os de Jean-Louis Comolli e Jean Narboni, "Cinéma/Ideologie/ Critique" 1 e 2, Cahiers du Cinéma 216 e 217 (1969); o de Jean-Paul Fargier, "La parenthèse et le détour", Cinéthique 5 (1969); eo de Gerard Leblanc, "Direction", Cinéthique 5 (1969).

(8) Sobre a teoria da

desconstrução, ver Rodowick, pp. 67-110; Casetti, pp. 213-220; e Ismail Xavier, 0 discurso cinematográfico: a opacidade e a transparência (Rio de Janeiro: Paz e Terra, 1984), pp. 123-138.

(9) Cinéthique $7 / 8$ (1970).

(10) Sobre a teoria do dispositivo de Baudry, ver, por exemplo, Rodowick, pp. 89-97; Lapsieye Westlake, pp. 79-83; Casetti, pp. 221-222; Xavier, pp. 128-130; e Barbara Klinger, "In retrospect: film studies today", Yale Journal of

Criticism 2, 1 (1988), pp. 129-136. ((11i) Cinéthique 13 (1972). 
(12) Nöel Burch e Jorge Dana, "Propositions", Afterimage 5 (1974).

(13) Sobre esta fase do pensamento de Burch, ver Rodowick, pp. 111-125; Casetti, pp. 230-231; e Xavier, p. 136. (14) Christian Metz, "Le signifiant imaginaire", Communications 23 (1975).

(15) Sobre esta fase do pensamento de Metz, ver, por exemplo, Lapsleye Westlake, pp. 81-86; e Casetti, pp. 196-200. (16) Sobre o antinarrativismo, ver Rodowick, pp. 126-46. (17) Sareen 16, 3 (1975). tido, de certas posições teóricas anteriores ao 68. Em um movimento inverso, Nöel Burch, logo a seguir, protagoniza um recrudescimento do formalismo político, especialmente no ensaio "Propositions", redigido em francês e publicado em tradução na Inglaterra em 1974'2. Mas os efeitos da reflexão de Burch igualmente configuram uma regressão, em sua retomada de uma teoria da desconstrução em que a concepção de espectador é apenas sugerida ${ }^{13}$. Um terceiro desdobramento ocorre, finalmente, com a teorização de Christian Metz sobre o significante imaginário ${ }^{14}$ Metz elabora a partir da teoria do dispositivo de Baudry, agregando, à investigação do papel da especularidade produzida por este, um estudo da função das pulsões voyeurísticas e fetichísticas no posicionamento do sujeito transcendental operado pelo dispositivo cinematográfico ${ }^{15}$. Esta dispersão do front teórico é reveladora dos impasses estabelecidos pela tensão entre um programa modernista formalist e sua pretensão de contemplar a História e o espectador, e encaminha um esvaziamento do projeto modernista-político no contexto francês.

Já em 1971 se inicia, no entanto, a importação das teorias francesas por Screen, bancada especialmente por Stephen Heath e Colin MacCabe, exalunos de Barthes, Derrida, Althusser e Lacan em Paris, que vão ocupar posição de destaque no conselho editorial da revista. A partir de 1974, quando, após as traduções, advém a fase propriamente inovadora ou produtiva da screentheory, pode-se afirmar que as mesmas três tendências conflitantes observadas na França entre 1972 e 1975 reaparecem nas diferentes linhas de trabalho abrigadas na revista. Neste sentido, Screen sucede de forma bastante fidedigna a Cinéthique e aos Cahiers, uma vez que, ao dar prosseguimento à sua elaboração teórica, retoma também as divergências legadas por ela. Assim, no campo formalista, as teorias antinarrativas e anti-representacionalistas associadas ao cinema materialista-estrutural de Peter Gidal e Malcolm LeGrice parecem reprisar o desconstru- cionismo a-historicizante de Burch ${ }^{16}$. Esta corrente é frontalmente combatida pelo pós-brechtianismo cinematográfico que domina a screen-theory entre 1974 e 1975, provocando o primeiro grande dissenso teórico na revista. Paralelamente, em 1975, Laura Mulvey dá seqüência à teoria do dispositivo de Baudry e Metz, ao mobilizar seu arsenal conceitual na escritura do ensaio seminal da teoria feminista do cinema, "Visual pleasure and narrative cinema"17 A resolução do conflito entre o materialismo estrutural e o pós-brechtianismo, em favor deste último, institui-o como mainstream da screen-theory na sua primeira fase de efetiva produção. Para os ensaístas pós-brechtianos (Peter Wollen, Stephen Heath, Colin MacCabe, Ben Brewster, Stanley Mitchell, Constance Penley e Janet Bergstrom, entre outros), impõe-se como prioridade a busca de uma maior aproximação à realidade histórica, através da apropriação das teses revolucionárias de Brecht que associam uma técnica textual, o "distanciamento", à produção de conhecimento sobre a realidade. De certa forma, o que se elabora é uma conciliação das estratégias formais modernistas com a noção de realismo. Esta ânsia por uma historicização também se faz presente na concepção pós-brechtiana do espectador. A grosso modo, propõe-se o rompimento da posição identificatória do sujeito transcendental por meio do reposicionamento espectatorial para um lugar de produção de sentidos, processo este que é deflagrado pelas imagens contraditórias da realidade disponibilizadas enquanto técnica de distanciamento. Pode-se compreender o pósbrechtianismo, portanto, como uma tentativa de resolver as tensões entre formalismo, História e espectador. E para tanto, o pensamento de Brecht vem tomar lugar, ao lado dos de Althusser e de Lacan, nas fundações teóricas modernista-políticas.

No entanto, apesar da redobrada atenção pós-brechtiana à História, a presença desta mantém-se limitada a uma inscrição meramente textual, permanecendo ignorada sua ação sobre 
a relação entre filme e espectador. Heath e MacCabe empreendem, então, os derradeiros esforços do modernismo político no sentido da historicização do espectador, inaugurando, ao final de 1975, uma segunda fase da screentheory a que Lapsiey e Westlake denominam "dialética do sujeito". Em sintonia com o cenário mais amplo do pensamento acadêmico de esquerda em meados da década, onde se assiste ao desmoronamento do paradigma marxista-estruturalista althusseriano (resultado de ataques em boa parte pautados por uma crítica à sua desviante apropriação da psicanálise lacaniana), os dois autores promovem uma ampliação da presença do pensamento de Lacan em Screen, em substituição ao de Althusser. Sua leitura mais apurada de Lacan, sem a mediação do althusserianismo, vem descrever um sujeito desde sempre em processo, irredutível à unidade e homogeneização típicas da identificação especular. Heath e MacCabe levam a efeito, por isso, uma profunda revisão do conceito de sujeito transcendental de Baudry, onde substituem a idéia de um posicionamento pela idéia de contensão, tãosomente, de um espectador em permanente movimento. É esta idéia de sujeito em processo, enfim, que configura espaços para uma maior historicização do espectador, possibilitando um primeiro reconhecimento dos influxos do extra-textual sobre este. Tal reconhecimento se mostra bastante modesto, no entanto, uma vez que estabelece uma forte contradição com o inevitável determinismo textual que Heath e MacCabe, como teóricos modernista-políticos, insistem em sustentar. A partir deste momento, porém, tantas são as contradições e tensões experimentadas que à screentheory resta somente admitir a falácia de seu textualismo, o que é realizado no ensaio de Willemen, de 1978.

A screen-theory, portanto, apresenta duas etapas principais bastante distintas, o pós-brechtianismo e a dialética do sujeito, que se somam às duas verificadas em Cinéthique e nos Cahiers, para compor o corpus teórico mais abrangente do modernismo político. Ao articular o desenvolvimento teórico ao longo destas diferentes etapas, está a obstinação em buscar soluções para a contradição insuperável entre um determinismo textual definidor e o desejo de uma concepção historicizada do espectador. Creio que se pode identificar, na teorização modernista-política, o seguinte deslocamento conceitual interno: partindo de um desenho inicial onde o sujeito-espectador comparece apenas implicitamente como objeto de subjetivação (na teoria da desconstrução), elaborase uma concepção detalhada do posicionamento subjetivo (na teoria do dispositivo), admite-se a seguir a necessidade de contemplar o histórico, ainda que sempre a nível textual (no pós-brechtianismo) e, em um último e infrutífero esforço de fuga ao determinismo textual, aborda-se a condição do sujeito-espectador como a de constituído/constituidor, em sua relação com o texto (na dialética do sujeito). Nesta altura, a crítica de Willemen vem apenas consagrar a inviabilidade da compreensão apriorística do espectador com base exclusiva nas propriedades textuais, reclamando a necessidade da abertura da teoria aos influxos do contexto de recepção. Com isso, opera-se a passagem de um absoluto textualismo inicial a um contextualismo.

Passo a seguir ao mapeamento propriamente dito das duas fases centrais que identifico na screen-theory, o pós-brechtianismo cinematográfico e a dialética do sujeito. Deliberadamente, dado este ordenamento que confiro ao mapeamento, não examino o trabalho de Laura Mulvey, de importância crucial para o desenvolvimento da teoria feminista do cinema. Assim procedo porque, primeiramente, em que pese sua relevância histórico-teórica, sua reflexão é mais próxima da teoria do dispositivo francesa que dos desdobramentos efetivamente inovadores da screentheory. Isso não bastasse, seu trabalho já tem recebido suficiente atenção por parte dos historiadores da teoria no país. 
(18) Suas teses a respeito das duas vanguardas têm início na "Conclusão" à terceira edição de seu Signs and meaning in the cinema (Bloomington and London: Indiana University Press, 1972), sendo aprofundadas nos ensaios "The two avant-gardes", Studio International 190, 978 (1975)e "Ontotogy and materialism in film", Screen 17, 1 (1976). (19) Os textos mais representativos do materialismo estrutural são os de Peter Gidal, "Definition and theory of the current avant-garde: materialist/structural film", Studio International 187, 963 (1974), e Malcolm LeGrice, Abstract film and beyond (London: Studio Vista, 1977).
O pós-brechtianismo cinematográfico

Primeira contribuição inovadora oferecida pela screen-theory, o pósbrechtianismo surge como resposta à identificação de um recrudescimento formalista no interior do modernismo político, consumado nas obras de Burch e dos materialistas-estruturais Gidal e LeGrice. Institucionalmente, é responsável pelo dissenso interno que opõe os defensores de duas correntes distintas da vanguarda, a pósbrechtiana e a experimentalista. Contra o formalismo desta última, autores como Wollen, Heath, MacCabe, Brewster, Mitchell, Penley e Bergstrom promovem o resgate das teses brechtianas revolucionárias para o teatro, reelaboradas dentro da sofisticada moldura semiolacano-althussseriana do modernismo político. Com vistas à superação dos excessos formalistas a-historicizantes, seu objetivo é a defesa de um contracinema fundado sobre o conceito brechtiano de distanciamento (Verfremdung), para que tal cinema possa ser, além de auto-reflexivo, também produtor de conhecimento sobre a realidade. Ao mesmo tempo, graças a esta aproximação à História, podem efetuar uma primeira, ainda que incipiente, separação teórica entre o texto fílmico e o espectador.

A oposição entre as duas vanguardas, a experimentalista e a pósbrechtiana, é explicitada por Wollen já a partir de $1972^{18}$. O que ele postula, na verdade, é a existência de duas tradições vanguardistas bastante concorrentes ao longo de toda a história do cinema. Uma primeira tradição, a que ele denomina "pictórica", se origina no experimentalismo francês e alemão dos anos 20 , tem seqüência com a migração deste experimentalismo ao cenário americano do pós-guerra, e atinge seu apogeu, na década de 60, no New American Cinema e no cinema estrutural, seja na versão americana deste último ou na linha materialista-estrutural britânica. A outra, designada como "literária", tem raízes em Eisenstein e Vertov e culmina no pós-brechtianismo do princípio dos anos 70 , embora, por vezes, este último seja também indicado por Wollen como uma desejada convergência entre as duas linhas. Wollen termina por acusar a vanguarda experimentalista da proposição de um "materiaiismo ontológico", que resulta de sua investigação puramente formal do substrato material do cinema, e tem como conseqüência a exclusão de toda e qualquer referência à realidade e à História. A acusação inclui, evidentemente, o cinema materialista-estrutural britânico de Gidal e LeGrice, o qual, embora represente uma politização, acompanhada de severa crítica, da vanguarda estrutural "idealista e burguesa" americana, propõe um antinarrativismo e um anti-representacionalismo que é perfeito exemplar da negação experimentalista do referente histórico ${ }^{19}$. Ë este pecado, de acordo com Wollen, que a estética pósbrechtiana vem contornar, em sua realização de um trabalho tanto no plano do significante como no do significado.

A relação dos teóricos pósbrechtianos com seus antecessores das teorias da desconstrução e do dispositivo é de reelaboração crítica. Procuram, por um lado, corrigir os excessos formalistas autorizados pelo desconstrucionismo de Cinéthique e dos Cahiers. À primeira vista, pode surpreender a reclamação, por parte de Wollen e de seus colegas, de um trabalho que contemple não apenas a revelação da materialidade dos significantes, mas uma maior compreensão da realidade histórica. Afinal, é preciso lembrar que, já em 1969, Fargier, Leblanc, Comolli e Narboni recomendam como fundamental uma "ação em dupla frente", sobre o significante e o significado. Ocorre que, apesar desta recomendação, a preocupação fundamental da cartilha desconstrucionista em Cinéthique e nos Cahiers é o trabalho investigativo e expositivo das formas textuais, o que fica demonstrado em seu empenho na denúncia do cinema político que opera exclusivamente no plano do conteúdo. Ë esta ênfase formalista que termina por autorizar os excessos formalistas como os de Burch, Gidal e LeGrice. De toda maneira, os pósbrechtianos tratam apenas de corrigir os excessos da teoria da desconstrução, dando assim seqüência ao seu projeto. 
Também de continuidade é a relação do pós-brechtianismo com a teoria do dispositivo de Baudry e, mais tarde, Metz e Mulvey. Ela é tomada como pressuposto na abordagem pósbrechtiana ao sujeito-espectador, alcançando papel de destaque inclusive no municiamento do ataque dirigido à vanguarda experimentalista. Quando Constance Penley e Janet Bergstrom, por exemplo, se lançam ao exame critico do New American Cinema e, em particular, do materialismo estrutural de Gidal e LeGrice, usam como parâmetro o conceito de sujeito transcendental de Baudry e $\mathrm{Metz}^{20}$. Penley afirma que o programa de Gidal e LeGrice, em última instância, descende do credo modernista fenomenológico da vanguarda americana, corporificado nos escritos de Annette Michelson e Regina Cornwell, que se baseia na produção de conhecimento através dos atributos da consciência e da percepção ${ }^{21}$. Ela registra a sinceridade das intenções políticas dos materialistas-estruturais ingleses, duvidando, no entanto, da eficácia de seu projeto de "expansão da visão" promovido por um "cinema sobre o cinema". Para ela, o incremento da consciência sobre os procedimentos e a materialidade fílmicos, por meio do treinamento perceptivo do espectador, nada oferece em contraposição às fundações psíquicas do cinema ilusionista, por sustentar-se precisamente sobre os mesmos mecanismos que, de acordo com Baudry, definem a constituição do sujeito transcendental. Segundo Penley, no fim das contas o que o cinema materialista-estrutural de Gidal e LeGrice vem promover, ironicamente, é um inadvertido posicionamento de seu espectador como um "sujeito 'materialista' transcendental".

Os desvios a-historicizantes do projeto desconstrucionista são corrigidos por meio de uma conciliação de suas estratégias formais modernistas com a noção brechtiana de realismo. A produção de conhecimento sobre a realidade, segundo Brecht, é obtida por meio da exposição de suas contradições decorrente da utilização das técnicas de distanciamento. Desta conciliação resultam, porém, tensões que começam a encaminhar o modernismo político a seu esgotamento teórico. A acomodação do pensamento de Brecht é alcançada a muito custo, visto ser o projeto modernista-político fundado justamente sobre uma rígida oposição binária entre realismo (o cinema dominante) e modernismo (o contracinema revolucionário). As contradições teóricas que se estabelecem são demonstradas de modo exemplar no debate que travam Mitchell e Brewster em tomo ao parentesco entre o conceito brechtiano de distanciamento e o trabalho dos formalistas russos e estruturalistas tchecos ${ }^{22}$. Mitchell reclama um alinhamento teórico não ao modernismo mas ao realismo, que segundo ele é o campo estético no qual Brecht se reconhece. Para tanto, com o objetivo de desqualificar o que identifica como a origem do formalismo modernista, dirige um agudo ataque ao conceito de estranhamento (ostranemie) de Shklovsky, cujo efeito de desautomatização perceptual ele denuncia como apenas mais uma das várias espécies de alienação burguesa, devido ao abandono da referência à realidade em favor de um mero jogo com os significantes. Em resposta, Brewster defende a tradição formalista/estruturalista, salientando a enorme distância que separa o conceito de autonomia da função poética em Jakobson de qualquer formalismo auto-suficiente. Ao mesmo tempo, ele entende perfeitamente compatíveis os procedimentos formais modernistas e o que ele considera uma indispensável contemplação da realidade histórica quando da construção do sentido no texto fílmico de vanguarda. Mas esta produção de conhecimento sobre a realidade, para ele, deve manterse na esfera teórica do modernismo, todo realismo sendo entendido como inevitavelmente ideológico. O confronto é facilmente resolvido em favor de Brewster, em função do óbvio desconforto do projeto modernista-político para com qualquer noção de realismo. Mas as tensões entre esta exclusão do realismo e a proposta de aproximação à realidade histórica instalam-se com força no pós-brechtianismo.
(20) A cuítica de Penleye Bergstrom pode ser encontrada em seu ensaio conjunto, "The avantgarde: history and theories", Screen 19, 3 (1978), e no de Penley, "The avant-garde and its imaginary", Camera Obscura 2 (1977). A influência do pósbrechtianismo se estende até $o$ final da década, embora, do ponto de vista histórico-teórico, ele já tenha sido, a esta altura, sucedido pela dialética do sujeito de Heath e Maccabe.

(21) Ver, por exemplo, Annette Michelson, "Screen/surface: the politics of illusionism "Artforum (1972) e Regina Cornwell, "Some formalist tendencies in the current American avant-garde", Studio International 184, 948 (1972). (22) Em Stanley Mitchell, "From Shklovsky to Brecht", Screen 15, 2 (1974), e Ben Brewster, "From Shklovsky to Brecht: a reply", Screen 15, 2 (1974). 
O texto pós-brechtiano maior é sem dúvida "Ontology and materialism in film", onde Wollen perfaz sua crítica definitiva ao experimentalismo. Analisando as nuances da produção cinematográfica e/ou teórica de figuras-chave do New American Cinema, do cinema estrutural americano e do cinema materialista-estrutural inglês, como Annette Michelson, Stan Brakhage, Paul Sharits, Peter Gidal e P. Adams Sitney, Wollen as faz equivaler em sua adoção de um "materialismo ontológico" segregador da dimensão semântica do texto fílmico. $\mathrm{O}$ autor constrói uma surpreendente aproximação entre as diversas técnicas formais apregoadas - antinarrativa, redução semiótica, auto-reflexividade, cinema sobre o cinema etc. - e o realismo de André Bazin. De acordo com ele, de um realismo ontológico idealista do teórico francês, obtido em função das propriedades revelatórias do registro fotográfico, e antitético a uma teoria semiológica em sua desconsideração do significante, passa-se no experimentalismo a um "realismo" ontológico materialista centrado na percepção do próprio substrato material do cinema como evento pró-fílmico, igualmente antisemiológico em sua exclusão de qualquer significado, denotatum ou referente que não seja intrínseco à materialidade física do filme. Nesta falácia ontológica, Wollen identifica o destino de uma vanguarda que, por entender a narrativa e a representação como intrinsecamente ideológicas, vislumbra num cinema puramente do significante o programa anti-ilusionista ideal, mas cai prisioneira na armadilha modernista greenberguiana da arte pela arte.

Em oposição a este materialismo ontológico experimentalista, Wollen oferece um "sentido pós-brechtiano de materialismo, que deve ter como preocupação a significância daquilo que é representado, a qual é localizada no mundo material e na história". Reconhecendo que todo texto é estruturado no plano do significante, Wollen postula que as estratégias formalistas de ação sobre o significante fílmico produzam não a interrupção ou destruição, mas uma intervenção sobre o processo de significação, que "transforme o sentido, altere ou negue o fluxo dos significados, desvie, subverta, converta". Esta operação é descrita como um deslocamento do significante com relação ao significado, que seja "afirmativo da primazia do primeiro sem de modo algum dissolver o segundo". E a exemplificar a linha de raciocínio, a cinematografia do Godard pós-68 (do Grupo Dziga-Vertov) é celebrada pela abertura de uma "rota alternativa entre o contentismo e o formalismo, um reconhecimento de que é possível trabalhar dentro do espaço aberto pela disjunção e deslocamento de significante e de significado", gerando novos sentidos.

A utilização das técnicas de distanciamento brechtianas, operantes através da exposição das contradições da realidade, tem implicações diretas também sobre a concepção de espectador do modernismo político. Heath, por exemplo, afirma que a ênfase mais óbvia do conceito brechtiano de distanciamento recai sem dúvida sobre a ruptura da unidade e continuidade da posição de identificação do espectador com o texto, estabelecendo uma distância com relação à "homogeneização ideológica da realidade" pelo cinema dominante e acarretando a instauração de uma nova subjetividade. Esta última é alcançada mediante a inclusão, no processo de produção do sentido, do "receptor", de forma que se estabeleça uma dialeticização das relações entre este, a realidade e o seu reflexo ilusionista ${ }^{23}$. Por seu lado, MacCabe elabora o conceito de "separação" para descrever estes efeitos do distanciamento, que ele descreve como um deslocamento do sujeito dentro da ideologia, provocando a passagem do espectador de uma posição de "petrificação" e "pseudodominância" à de produção de sentidos ${ }^{24}$. Em resumo, o cenário montado por Heath e MacCabe propõe o rompimento da posição identificatória do sujeito transcendental de Baudry mediante o reposicionamento do espectador para um lugar de produção de sentidos, a qual é efetuada a partir das imagens contraditórias da realidade disponibilizadas como técnica de 
distanciamento.

Dois conceitos de Heath, o de "desmontagem do espectador" e o de "deciframento produtivo", ao mesmo tempo em que sintetizam perfeitamente este processo, expõem também o quadro de séria inconsistência teórica interna de que se aproxima o modernismo político. A autonomização do espectador perante o texto, implicada na noção de sua participação decisiva na construção dos sentidos, é imediatamente negada em sua continuada identificação com as formas textuais. É o texto fílmico pós-brechtiano quem, em última análise, ativa a desmontagem do espectador, por meio de um seu reposicionamento subjetivo desideologizante. Ou seja, mantém-se o falacioso determinismo textual modernista-político: a aproximação do pós-brechtianismo à História dá-se tão somente no plano do texto, seguindo desconsiderados seus efeitos sobre a relação entre o filme e o espectador. É a tentativa de resolução deste impasse que anuncia, ao final, o advento de uma nova etapa da teorização, derradeiro esforço modernista-político na contemplação de um sujeito espectador historicizado.

\section{A dialética do sujeito}

Segunda fase produtiva da screen-theory, a dialética do sujeito de Heath e MacCabe representa os derradeiros esforços do modernismo político no sentido da resolução dos impasses entre o textualismo que o define e sua intenção de promover uma historicização da concepção de espectador. Os dois autores reelaboram sua reflexão pós-brechtiana sob a influência do desmoronamento internacional do pensamento althusseriano, o que lhes permite intensificar tanto quantitativa como qualitativamente a presença do lacanismo em suas bases teóricas. Isto vem configurar uma verdadeira segunda etapa do trabalho psicanlítico modernista-político, sucessora da teoria do dispositivo de Baudry, Metz e Mulvey, e pautada pela idéia de um sujeito sempre em movimento, e portanto jamais passível de um absoluto posicionamento pelo texto fílmicó. É a partir desta idéia de processo que Heath e MacCabe tentam encaminhar a tão desejada aproximação do espectador ao contexto histórico

As relações entre a dialética do sujeito e os estágios precedentes da teorização modernista-política revelam o grau de tensão interna que atinge o projeto teórico iniciado por Cinéthique e pelos Cahiers. Evidentemente, a crítica ao pós-brechtianismo é mitigada em razão da própria origem da obra de Heath e MacCabe naquele momento teórico. Por isso, os autores mantêm a defesa da vanguarda pós-brechtiana representada por Godard, Straub-Huillet e Oshima, bem como a denúncia do formalismo experimentalista e a urgência por uma representação textual da realidade. No entanto, buscam a resolução do impasse pós-brechtiano decorrente da negação do histórico como determinante da relação entre filme e espectador. Já com respeito à teoria do dispositivo, as distâncias se acentuam, em função do abandono do conceitual althusseriano e de sua ênfase sobre a fase do espelho. Mesmo assim, a atitude de Heath e MacCabe mostrase ainda mais como de correção do que de enfrentamento, pois o que promovem é uma complementação teórica por meio de aspectos antes negligenciados da obra de Lacan, vindo enriquecer a noção de posicionamento subjetivo especular ao relativizá-la com a idéia de um sujeito permanentemente dividido e em movimento. O mesmo não pode ser dito, porém, quanto à postura de Heath e MacCabe para com a teoria da desconstrução, a qual passa a ser alvo de intensas críticas, indicadoras, em última análise, da eminente ruptura dos alicerces do pensamento modernista-político. Enquanto na fase pós-brechtiana o desconstrucionismo é objeto apenas de um saneamento de seus vícios formalizantes, agora o que se verifica é o ataque frontal ao conceito. Segundo a dialética do sujeito, a simples desconstrução dos códigos do cinema dominante não é suficiente, sendo preciso um trabalho sobre o que Heath denomina o seu "endereçamento espectatorial" 25. A origem da dialética do sujeito
(25) No inglês, "spectatorial address". 
está no ataque de Heath à noção fun- gação de dois temas preferencias, o condante do modernismo político em suas três primeiras etapas de formação, a interpelação althusseriana ${ }^{26}$. Baseandose em Paul Hirst, ele aponta que "o mecapos nismo da interpelação pressupõe o sujeito que alegadamente constitui", uma vez que o indivíduo a ser posicionado ideologicamente deve já dispor de faculdades "subjetivas" para proceder ao "reconhecimento que o constituirá como sujeito". Não bastasse isso, segundo Heath a própria idéia de sujeito envolvida na noção de interpelação se opõe radicalmente à apresentada no modelo de Lacan. Althusser toma deste último fundamentalmente a análise dos mecanismos de constituição da identiceito psicanalítico de sutura e a narrativa. Em suas reflexões em tomo à sutura, o autor resgata e corrige a transosição do termo, elaborado pelo psicanalista lacaniano Jacques-Alain Miller, à área cinematográfica, efetuada inicialmente por Jean-Pierre Oudart no contexto francês do pós-maio de $68^{27}$. O intrincado conceito psicanalítico dá conta do permanente esforço de defesa do sujeito contra sua constituidora divisão na linguagem e a falta disso decorrente. Este empenho consiste em, através de uma pseudo-identificação, assumir uma totalidade imaginária, um conjunto de imagens no qual o ego dade verificados no estágio do espelho, tário. Oudart aplica o conceito ao cinema os quais se associam ao campo do imaginário e são portanto assimiláveis à sua noção de ideologia. São olvidados, porém, todos os processos posteriores envolvidos na construção da subjetividade, e com estes, os vários elementos psíquicos ligados ao domínio do simbólico. Decorre desta assimilação redutora que para Althusser a subjetividade é unificada, indivisa e por isso homogeneamente inserida e posicionada no universo do ideológico. Heath entende que na ótica lacaniana, ao contrário, o sujeito encontra-se sempre necessariamente em movimento, visto que, em lugar de uma unidade imaginária da identidade, o que há é divisão e diferença, uma não-identidade fundamental. Sendo assim, inexiste a possibilidade de uma construção unilateral de subjetividades pelos aparelhos ideológicos de estado. Por outro lado, a contemplação não apenas do imaginário, mas também do simbólico, implica que o sujeito sempre escape ou exceda às suas representações, nunca sendo por elas completamente posicionado ou capturado. Em lugar disso, o que há é uma subjetividade que a um só tempo é produto e

(26) A versão mais elaborada deste ataque se encontra em "Notes on suture", Screen 18, 4 (1977/78). (27) Jean-Pierre Oudart, "La suture, I eI", Cahiers du Cinéma 211, 212 (1969).

(28) Sareen 17, 3 (1976). produtora do sentido. Sujeito e sentido constróem-se um ao outro, portanto, em um processo dialético infindável. $\mathrm{Ou}$, nas palavras de Heath, "o sujeito cria os sentidos que o filme cria para ele".

A dialética do sujeito de Heath é apresentada na dimensão da investipara descrever os efeitos do sistema plano/contraplano, base da decupagem hollywoodiana, que procura "suturar" a descoberta, pelo espectador, da instância textual organizadora do campo visual, que ameaça romper a plenitude da imagem cinematográfica. Em seu resgate crítico do uso cinematográfico do conceito, Heath identifica vários problemas. O principal deles consiste na associação do conceito com a noção de interpelação, de que resulta a tendência, denunciada pela dialética do sujeito, a enfatizar o imaginário às custas do simbólico, e a unidade-às custas da divisão da subjetividade. Heath alega que, ao contrário, a sutura atua precisamente nos limites desta divisão, promovendo uma junção entre o imaginário e o simbólico. Em função disso, a operação está presente em toda e qualquer enunciação, e não apenas no plano/ contraplano, como pretende Oudart.

A investigação da representação fílmica da operação de sutura é efetuada por Heath em seu estudo sobre as estruturas da narrativa cinematográfica, que alcança sua versão definitiva no influente ensaio "Narrative Space", publicado em Screen em 197628. Este trabalho redunda na crítica mais séria ao programa desconstrutivista, assentada sobre dois pontos principais: o primeiro, de que o cinema hollywoodiano promove não o ocultamento, mas o contenimento dos sinais de sua produção, e o 
segundo, de que a desconstrução dos códigos do cinema clássico é insuficiente para uma intervenção política, devendo-se ter como alvo, ao invés disso, as formas de enderaçamento espectatorial instrumentalizadas pela narrativa ilusionista. Ironicamente, Heath retoma a análise da impressão de realidade hollywoodiana iniciada por Cinéthique e Cahiers, terminando por prover a mais sofisticada e efetiva descrição de sua produção textual, modificando significativamente, porém, o entendimento dos franceses com relação ao tema. A grande inovação do ensaísta consiste em reconhecer no movimento um elemento que, embora constitutivo da impressão de realidade, introduz por outro lado um intenso potencial disruptivo à transparência e à coerência narrativas. É em razão destas ameaças transgressivas do componente espacial do cinematográfico que o "excesso" em forma de mobilidade deve ser contido, por intermédio da fórmula fundamental para Heath da "transformação do espaço em lugar", ou, em outras palavras, em "espaço narrativo". Isto implica em que aquilo que é visto (seen) tome-se cena (scene), ou seja, que o significante remeta de forma transparente a um significado. No entanto, esta organização repressiva do movimento nunca é total, admitindo invariavelmente momentos de excesso tão somente para em seguida contê-los, como exceções a confirmar a regra. Por isso, Heath afirma inexistir a invisibilidade ou ocultamento do processo produtivo da impressão de realidade, ocorrendo um movimento muito mais sutil, de contenimento do excesso pela narrativização. Esta operação de contenimento e regulação, em que uma ausência, uma falta é incessantemente recapturada no filme, compõe o endereçamento espectatorial do filme clássico, que nada mais é que o próprio processo de sutura. Portanto, segundo Heath, é na dimensão destes mecanismos de endereçamento contidos na narrativa que um contracinema deve operar, e não na destruição da narrativa ou na desconstrução pura e simples de seus códigos.
Enfim, o sujeito-espectador em Heath deve ser compreendido através de duas modificações cruciais por ele introduzidas com relação à teoria do dispositivo. Em primeiro lugar, o aprofundamento de sua leitura lacaniana aponta um sujeito agora desde sempre em processo, em função de sua divisão e heterogeneidade constitutivas, e que por isso é irredutível a uma identidade com as formas textuais. Segundo, sua revisão do conceito de sutura descreve um constante movimento entre o imaginário e o simbólico, entre completude e falta, resultantes de um endereçamento narrativo fundado sobre o contenimento e não a eliminação do excesso e da disrupção. Por isso, enquanto para seus predecessores dispositivistas e pós-brechtianos o reposicionamento ou deslocamento do sujeito deriva necessariamente do movimento do próprio texto (o revolucionário, naturalmente), para Heath o sujeito-espectador está por definição em movimento, independente do texto fílmico. Por outro lado, em sua relação com o texto dominante, em lugar de ser fixado em posição por este e depois mantido posicionado contra ameaças disruptivas, ele pode apenas ser contido, suas energias reguladas pela organização narrativa das imagens.

É esta noção central de processo presente na concepção da subjetividade de Heath que o impele a uma aceitação da história como elemento participante na determinação dos sentidos do texto fílmico. Ele afirma que "há uma história concreta da construção do indivíduo como sujeito e esta história é também a construção social do sujeito", de modo que "não é que haja antes de tudo a construção de um sujeito para formações ideológicas e então o posicionamento, nestas formações, deste suporte subjetivo construído, o que há é que os dois processos são um, em uma espécie de simultaneidade necessária - como a frente e o verso de uma folha de papel" 29 .

Neste trecho revelam-se claramente, no entanto, as condições ainda incipientes de reconhecimento da relação, externa ao texto, entre história e
(29) Heath, "Screen images, film memory" Edinburgh Magazine 1976, p. 40. 
espectador no momento da leitura. A aceitação do influxo contextual das formações sociais sobre a recepção da obra fílmica ocorre, ainda, apenas na admissão de uma história concreta da construção do sujeito-espectador, que embora "simultânea" ao posicionamento deste pelo texto, ocorre desvinculada de um ato específico de interpretação textual socialmente contextualizada. Ao mesmo tempo, é mantido um espaço fundamental e privilegiado para o estudo da constituição do espectador pelas formas do texto, mais especificamente, no caso, do endereçamento espectatorial disponibilizado na narrativa.

De toda maneira, as reflexões de Colin MacCabe realizadas no universo da dialética do sujeito vêm encurtar ainda mais a distância modernista-política para com o contextual. Como em Heath, MacCabe realiza esta aproximação à relação história/espectador a partir de um aprofundamento da influência lacaniana, paralela ao abandono do suporte althusseriano encontrado até o pós-brechtianismo. MacCabe prefere abster-se, no entanto, de considerações em tomo à sutura para privilegiar uma reformulação do próprio conceito de especularidade dominante, em termos que contemplem não apenas o imaginário mas também o simbólico. MacCabe aponta a presença do simbólico já na própria experiência do estágio infantil do espelho. Para ele, isto é o resultado da presença do olhar materno no reflexo especular, o qual, se cumpre o papel de avalização da imagem infantil, só o faz às custas da introdução de uma diferença onde deveria haver apenas semelhança e identidade. Ou seja, o simbólico, que se vincula ao reconhecimento da existência de um mundo independente de nossa consciência, já comparece no mundo infantil antes mesmo da entrada definitiva da criança em seu domínio, inaugurando uma permanente oscilação do sujeito entre plenitude e falta, imaginário e simbólico. Para MacCabe, a distinção entre estes dois domínios pode ser entendida no cinema em termos de um contraste entre o "ponto de vista" e o "olhar". O primei- ro, que relaciona o espectador a um objeto na tela, oferece a primazia de uma visão unitária e dominante, enquanto o segundo, associado à representação do olhar dos personagens, posiciona como objeto o próprio espectador e introduz um lugar de onde este pode ser olhado e ameaçado em sua plenitude. MacCabe recorda então a análise freudiana do jogo infantil "fort/da", onde a criança experimenta, alternadamente, a presença e a ausência de um objeto desejado amarrado a uma corda. Esta dialética do prazer, segundo o autor, é reproduzida no cinema hollywoodiano por meio da dinâmica entre ponto de vista e olhar. Diversamente de Heath, MacCabe organiza suas reflexões em tomo ao sujeito-espectador desde uma detida investigação do realismo do texto clássico hollywoodiano.'É este destaque dado ao tema do realismo que termina por levar a uma maior consideração da inserção histórica do espectador como influxo atuante sobre as interpretações textuais. As teses de MacCabe sobre o realismo e as relações de subjetividade implicadas nesta noção recebem sua formulação mais acabada no conhecido artigo "Theory and film: principies of realism and pleasure", publicado em Screen também em 1976, juntamente com o artigo de Heath sobre o espaço narrativo ${ }^{30}$. O ensaio constitui uma reelaboração das reflexões iniciadas ainda no marco teórico do pósbrechtianismo ${ }^{31}$. O conceito de "texto realista clássico" avançado naquele momento dispõe sobre uma produção , articulada e deliberadamente ocultada de real no plano do texto, obtida através da hierarquização dos vários discursos presentes no filme em que um deles, dominante, age de forma metalingüística sobre os demais, assumindo assim a condição de parâmetro de realidade. Em seu novo artigo, MacCabe revê as teses do texto anterior, incidentes no impasse pós-brechtiano entre a reclamação de um sujeito produtor e a negação, típica da teoria do dispositivo, da relação deste com o contexto histórico de recepção da obra. Se em sua formulação pós-brechtiana o realismo era vinculado à hierarquização dos discursos presen- 
tes no filme, ocultadora da condição de articulação do real e posicionadora do sujeito em um regime de dominância especular, MacCabe destaca agora as potencialidades disruptivas da imagem associadas à permanente ameaça subjetiva da falta. O ocultamento da produção do real está desta forma sempre a perigo, e é no prazer oferecido como compensação aos riscos subjetivos que os efeitos de realismo são alcançados, através da garantia alentadora do ponto de vista. Esta noção de realismo de MacCabe, porém, somente se completa a partir da complementação da ação destes mecanismos textuais e subjetivos por uma produção contextual e historicizada do conceito pelas audiências. Neste sentido, a aproximação à história característica da dialética do sujeito, resultante da descrição de um sujeito em processo e por isso independente do texto, é buscada por MacCabe ainda mais intensamente que no trabalho paralelo de Heath. Sua definição de realismo abrange então não apenas os aspectos textuais da dinâmica entre ponto de vista e olhar, mas também as representações da noção de realismo compartilhadas pelo público em uma determinada situação histórica de recepção. Sendo assim, "a audiência e suas representações são os parâmetros do 'realismo' de qualquer filme ou obra de arte - não uma realidade pré-existente que eles somente refletem". Ou seja, o movimento do espectador entre o simbólico e o imaginário não é atem-Epílogo poral, mas historicizado. Com isso, a rea- O artigo "Notes on subjectivity", pufirmação textual do ponto de vista pode ser compreendida, acima de tudo, como uma tentativa de remoção do espectador das contradições social e historicamente encontradas.

Mesmo assim, ainda que avançando na comparação com a obra de Heath, e em que pese sua flagrante autoconsciência dos problemas que se procuram contornar, um balanço da refle- obra cinematográfica ${ }^{33}$. Colaborador xão de MacCabe demonstra a incapacidade de superação dos impasses anteriormente identificados no pósbrechtianismo. Na verdade, por maior que seja o esforço feito, ambos os autores voltam a reincidir no determinismo textual que, afinal de contas, é aspecto definidor do projeto modernista-político como um todo. De modo geral, o fato é que as considerações sobre a importância do contexto histórico de recepção sobre a relação texto/espectador vêm aparecer somente na condição de ressalva ou apêndice à investigação central, que permanece sendo sempre a das estruturas textuais como posicionadoras do sujeito-espectador. Se há o reconhecimento da história como determinante das interpretações textuais, é no texto fílmico, no entanto, que segue-se buscando o instrumento de ruptura do contenimento ideológico do espectador, mesmo que o lugar agora reservado a este seja não mais o de uma fixidez mas o de processo e heterogeneidade. Em última instância, a historicização do sujeito permanece dependente da complexidade e da contradição introduzidas por um possível texto revolucionário, mantendo-se o espectador, frente ao filme dominante, integralmente contido pelas formas textuais. David Rodowick, ao comentar tais falácias no pensamento de Heath, utiliza as próprias palavras deste último para referir-se, em tom de ìronia, às relações entre espectador $\mathrm{e}$ texto como determinadas pelo "espectador que este imagina" 32 . Ou seja, na dialética do sujeito que é estabelecida, o sujeito somente é constituidor na medida em que esta capacidade lhe é oferecida pelo texto.

$\mathrm{O}$ artigo "Notes on subjectivity", pu-
blicado por Paul Willemen em Screen, em 1978, demarca os limites históricoteóricos da screen-theory e do modernismo político, em sua ruptura epsitemológica e metodológica rumo a um contextualismo. É Willemen que produz o reconhecimento definitivo, agora teoricamente consistente, da ação do contexto de recepção sobre as interpretações da assíduo da revista durante as etapas anteriores da screen-theory, ele é o primeiro a referir-se às determinações extra-textuais de uma forma convicta e, por isso mesmo, realmente eficaz.

Willemen procede a uma explicitação de algumas noções já introduzi-
(32) Rodowick, p. 207. (33) Screen 19, 1 (1978). 
das por Heath e MacCabe durante a etapa da dialética do sujeito. Assim, refere, por exemplo, que as versões teóricas puramente textualistas retiram o texto da ideologia, das formações sociais e da história, fazendo o mesmo com o espectador, uma vez que esse é considerado inscrito no texto. Por causa disso, aponta a necessidade de investigação do "extra-texto" (outside-of-the-text), composto pelas diversas formações discursivas em constante disputa. Para ele, a produção de sentidos não depende apenas da efetividade de um sistema de representação, mas é determinada pela conjuntura das práticas discursivas, econômicas e políticas que produzem os sujeitos na história. Estas observações, que no momento da dialética do sujeito já existem de forma incipiente, mas insustentável em vista do determinismo textual ainda dominante, são articuladas por Willemen de uma maneira bastante mais sólida. $\mathrm{O}$ autor é o primeiro a apontar, por exemplo, que as leituras de um filme são imprevisíveis, podendo estes ser mobilizados, pelos discursos extra-textuais, para projetos diversos e mesmo contraditórios. Neste sentido, as análises textuais não mais elucidam o texto, mas somente o ativam, resumindo-se a isto seu papel. Por isto, nesta situação de intensa disputa discursiva contextual, a leitura progressista é não aquela que produz sentidos progressistas, mas a que ataca leituras conservadoras.

O reconhecimento da ação da instância contextual no processo da recepção fílmica é lento e gradual, afirmando-se efetivamente apenas no decorrer dos anos 80 , especialmente no trabalho dos estudos culturais. Os efeitos do artigo de Willemen, no entanto, são decisivos, especialmente se se considera que os próprios teóricos modernista-políticos já anseiam, nesta altura, por soluções mais definitivas para seus impasses. A partir deste momento, a screen-theory e o modernismo político experimentam um intenso movimento de implosão teórica, sendo sucedidos, como mainstream teórico, pelos estudos culturais e pelo cognitivismo. Cumprese assim, com o trabalho da revista, o grande deslocamento teórico e institucional que leva o centro da teorização em cinema desde a França ao mundo anglo-americano, e suas bases desde um textualismo a um contextualismo.

\section{Bibliografia do Artigo}

BERGSTROM, Janet, e PENLEY, Constance; Screen, $\mathrm{n}^{\circ}$ 19; 1978.

BORDWELL, David, e CARROLL, Noël (org.); Post-theory: reconstructing film studies, Madison: University of Wisconsin Press; 1996.

BREWSTER, Ben; Screen, nº 15; 1974.

BURCH, Nöel, e DANA, Jorge; Afterimage, n $5 ; 1974$.

CASETTI, Francesco; Teorias del cine, Madri: Catedra; 1994.

Cinéthique, $\mathrm{n}^{\circ} 7 ; 1970$.

Cinéthique, $n^{\circ} 8 ; 1970$.

Cinéthique, $\mathrm{n}^{\circ} 13 ; 1972$.

COMOLLI, Jean-Louis, e NARBONI, Jean; Cahiers du Cinema, 216

/ 217; 1969. 
CORNWELL, Regina; Studio International, 184, 948; 1972.

FARGIER, Jean-Paul; Cinéthique, n5; 1969.

GIDAL, Peter; Studio International, 187, 963; 1974.

HARVEY, Sylvia; May 68 and film culture, London: British Film Institute; 1978. ; Screen, Chicago, USA, 3,1; 1982.

HEATH, Stephen; Screen, Chicago, USA, 16,4; 1975 / 76. ; Edinburgh Magazine; 1976.

KLINGER, Barbara; Yale Journal of Criticism, 2,1; 1988.

LAPSLEY, Robert, e WESTLAKE, Michael; Film theory: an introduction; Manchester: ManchesterUniversity Press; 1988.

LEBLANC, Gerard; Cinéthique, n5; 1969.

LEGRICE, Malcolm; Abstract film and beyond; London: Studio Vista; 1977.

MACCABE, Colin; Screen, Chicago, USA, 16,4; 1975 / 76) ; Tracking the signifier: theoretical essays: film, linguistics, literature; Minneapolis: University of Minnesota Press; 1985.

MAYNE, Judith; Cinema and spectatorship; Londres: Routledge; 1993

METZ, Christian; Communications, n²3; 1975.

MICHELSON, Annette; Artforum; 1972.

MITCHELL, Stanley; Screen, Chicago, USA, 15, 2; 1974.

OUDART, Jean-Pierre; Cahiers du Cinéma, 211,212; 1969.

PENLEY, Constance; Camera Obscura, n²; 1977.

RODOWICK, David; The crisis of political modernism: criticism and ideology in contemporary film theory; Berkeley: University of California Press; 1994.

Screen, Chicago, USA, 15, 2; 1974.

Screen, Chicago, USA, 16, 3; 1975. 
Screen, Chicago, USA, 17,3; 1976.

Screen, Chicago, USA, 18,4; 1977 / 78.

Screen, 19,1; 1978.

XAVIER, Ismail; O discurso cinematográfico: a opacidade e a transparência; Rio de Janeiro: Paz e Terra; 1984.

WOLLEN, Peter; Signs and meaning in the cinema; Bloomington and London: Indiana University Press; 1972. ; Studio International, 190,978; 1975. ; Screen, 17, 1; 1976. 